International Journal of Current Advanced Research

ISSN: O: 2319-6475, ISSN: P: 2319 - 6505, Impact Factor: SJIF: 5.995

Available Online at www.journalijcar.org

Volume 6; Issue 5; May 2017; Page No. 3592-3594

DOI: http://dx.doi.org/10.24327/ijcar.2017.3594.0323

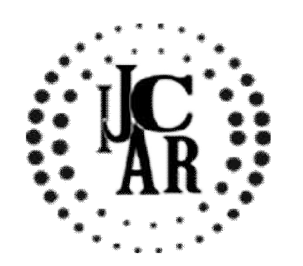

Research Article

\title{
A STUDY OF ANEMIA AND DIABETIC COMPLICATIONS IN PATIENTS WITH TYPE IIDIABETES MELLITUS IN A TERTIARY CARE CENTRE
}

\section{Hemani K and Kannan Rajendran}

Depertmentof General Medicine, Saveetha Medical College and Hospital, Saveetha University, Chennai, Tamil nadu, India

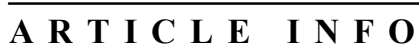

\section{Article History:}

Received $17^{\text {th }}$ February, 2017

Received in revised form $12^{\text {th }}$ March, 2017

Accepted $2^{\text {nd }}$ April, 2017

Published online $28^{\text {th }}$ May, 2017

\section{Key words:}

Type II diabetes mellitus, anemia, iron deficiency anemia, diabetic macrovascular disorders

\begin{abstract}
A B S T R A C T
Objective and background: Diabetes mellitus is a common metabolic disorder defined byhyperglycemea due to, insulin deficiency in Type IDM or insulin resistance as in Type II DM. The disorder when left unattended can compromise on the quality of life particularly with the development of complications. This study attempts to study the complications in patients with DM Type II in a tertiary care centre.

Method: The present study was done at a tertiary care centre. Hospital records of 122 patients who attended the hospital with the diagnosis of Type IIDM were retreieved for this study, to analyse anaemia and other associated comorbidities present in those patients.

Result: The results revealed that, of the 122 records seen $62.2 \%$ were females and $37.7 \%$ were men. Aged between 29-68 years. Of them, 71.3\% had anaemia. From peripheral smear study, it was inferred that $59.7 \%$ patients had normocytic anaemia, and39.8\% had microcytic anaemia and $1.4 \%$ hadmacrocytic anaemia.

Amongst the common complications associated with Type II DM, 52.63\% patients had diabetic neuropathy, $9.64 \%$ had diabetic nephropathy, $14.03 \%$ had diabetic foot ulcer and $7.89 \%$ had diabetic retinopathy

Conclusion: Records from the tertiary care centre revealed, that, Type II DM was prevalent more in women (62.2\%) than in men $(37.7 \%)$. The most common type of anaemia was normocyticnormochromic type seen in $59.7 \%$ cases. Amongst the macrovascular complications diabetic neuropathy was the most prevalent seen in $52.63 \%$ cases.
\end{abstract}

Copyright $₫ 2017$ Hemani K and Kannan Rajendran. This is an open access article distributed under the Creative Commons Attribution License, which permits unrestricted use, distribution, and reproduction in any medium, provided the original work is properly cited.

\section{INTRODUCTION}

Diabetes mellitus (DM) isa metabolic disorder which is characterised by a hyperglycaemic state and classified asType I DM and Type II DM. DM I is characterised by destruction of pancreatic beta cells and absence of endogenous insulin. Type II DM is characterised by insulin resistance at tissue level. Thus absence and resistance to insulin reduces the uptake of glucose especially by the muscle tissue and leads to accumulation of glucose in circulation leading to hyperglycaemia and disturbance to the homeostasis of the body. DM (1) is associated with the development of inflammation with elevation of proinflammatory cytokines, IL-1, IL-6, TNF and interferons INF-g.IL6, particularly has an antierythropoietic effect by altered sensitivity of progenitors to erythropoietin and apoptosis of immature erythrocytes precipitating anaemia called Anaemia of Chronic disease.

*Corresponding author: Hemani K

Depertmentof General Medicine, Saveetha Medical College and Hospital, Saveetha University, Chennai, Tamil nadu, India
Anaemic patients with DM Type II,express more inflammatory cytokines than the Type 1 diabetic patients and due to high levels of $\mathrm{C}$ reactive proteins and ferritin they have low iron content(2).

Inflammation and anaemia have, therefore, beenstated to be the prelude to all associated complications of DMlike, obesity and dyslipidemia, microcyticanaemia, cardiovascular disease due to dyslipidemia, micro and macro vascular kidney disease, retinopathy, reduced function of immune system exposing the diabetic individual to infection Type II Diabetes Mellitus (DM), most common among the diabetic population, isone medical condition seen to be on the increase globally. The etiology is multifactorial, due on the genetic constitution $(3,4)$, environmental factors, dietary changes, life style modifications $(5,6)$ and immunological factors. Thus this article aims to study Type II DM and itsassociated complications in patients who reported to a tertiary care unit.

\section{MATERIAL AND METHODS}

The present study was conducted in a tertiary care centre. Records of 122 patientswith Type II DM were identified for 
analysis Cases selected were marked according to WHO criteria for anemia with haemoglobin value $\mathrm{Hb}:<13$ in males and $\mathrm{Hb}:<12$ in females and microcytic anaemia with MCV less than $80 \mathrm{fl}$, normocytic anaemia with MCV between 80 100 and macrocyclic anaemia with MCV above 100fl. The patient records for the following data were scrutinized for analysis. Hb, HbAlc, Total leukocyte count (TLC), Differential leukocyte count (DLC), platelet count (PC), packed cell volume (PCV), blood urea, serum creatinine, peripheral smear study, fasting blood glucose(FBS), post prandial blood glucose (PPBS) and other investigations included echo, USG of abdomen, occult blood. Associated complications like, diabetic neuropathy diabetic nephropathy, diabetic foot ulcer and diabetic retinopathy were also noted.

\section{RESULT}

122 patients were studied, who were in the age group 29-68 years. The mean age was 52 years, of them76 (62.2\%) were females and $46(37.7 \%)$ males. Out of the 122 patients, only $8(6.55 \%)$ patients had no associated problems, where as $93.4 \%$ had one or more complications.87 (71.3\%) had anaemia. where the male and female population was $50 \%$ The peripheral smear report confirmed that 52(59.7\%) of anaemic patients had normocytic anaemia which was the most common, followed by microcytic anaemia in $34(39.8 \%)$ patients and $1(1.4 \%$ ) with macrocytic anaemia (Table 1), 2 had hepatomegaly, 5 had congestive heart failure, 8 had iron deficiency anaemia and 6 had chronic renal failure.

Amongst the Type IIDM, 96(78.68\%) had macrovascular complications of which men were 51(53.12\%) and women were $45(46.87 \%)$. $60(52.63 \%)$ patients had diabetic neuropathy, this was followed by $11(9.64 \%)$ diabetic nephropathy, 14 (14.03\%) diabetic foot ulcer and $9(7.89 \%)$ had diabetic retinopathy. (Table 2)

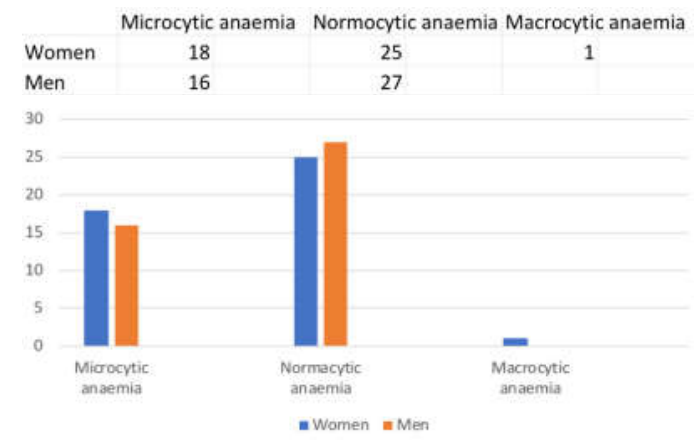

Table 187 out of $122(71.3 \%)$ had anaemia, of whom $44(50.57 \%)$ were women

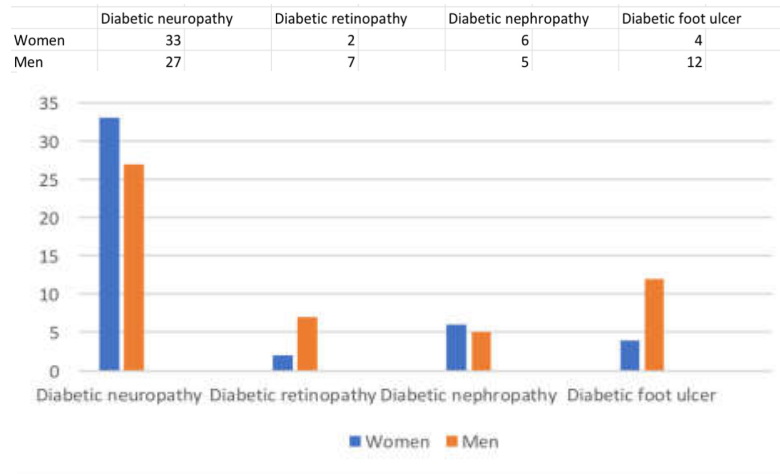

Table 2 Distribution of Macrovascularcomplications in Type II DM
Macrovascular complications was present in $78.68 \%$ of cases, more in men $(53.12 \%)$ than women $(46.87 \%)$, Diabetic neuropathy was most common 60(52.63\%) among others

\section{DISCUSSION}

Chronic diseases like DM are often accompanied by anaemia, called Anaemia of Chronic disease (7) This most often is due to infection, inflammation, and supression of immune status. Among the variousfactors responsible for the development of anemia in diabetes, symptomatic autonomic neuropathy which can lead to efferent sympathetic denervation of kidney, can further leadto reduced erythropoietin production (8), thereby being more debilitating in nature.

The combined effect of inflammation and anaemia predisposes the risk of developing micro and macro vascular complications. Sherif et al (9) have reported that life span of diabetic patients with anemia is less as compared to patients without anemia

Rathod et al (10) reported that prevalence of anemia among male and female was almost similar. Griac et al.(11) performed a similar study and reported higher prevalence of anemia in male (17.8\%) population as compared to females $(11.8 \%)$. . but in present study, the prevalence of anemia was $50.57 \%$ female population and $50.1 \%$ in males (Table 1 ) Sharif et al (9) reported very high incidence of anaemia (63\%) among diabetes patients, Rathod 18\% (10)] Al Salman [12] reported 55.5\% Jonas and Smith [13] 19-25\%, and Merlin(14) 5-16\%. Adejumo et al (15), (15.3\%) and Bonakdaran et al.; (19.6\%) (16) In the present study it was $47 \%$. The high incidence of anaemia reported quite confirms the finding by Manoj (17). That all diabetics should be screened for anaemia to protect them from further complications Different factors like HbA1c levels, urinary albumin excretion rate and glomerular filtration rate are associated with anemic levels in a patient with diabetes(18). The same is confirmed in our study that except for 8 patients with Type II DM, all others had micro and macrovascular complications (93.12\%) 60 patients had diabetic neuropathy, which was the most common in both the genders. This was followed by 11 diabetic nephropathy, 16 diabetic foot ulcer and 9 diabetic retinopathy.(Table 2)

The 8 patients who had no other vascular problems, 3 were only recently diagnosed as Diabetic. Long standing diabetic pathology is however to be associated with more comorbidities but could not be elicited in this study.

\section{CONCLUSION}

In our study morewomen (62.2\%) than men (37.7\%) had Type II DM. The most common type of anaemia was normocyticnormochromic type seen in $59.7 \%$ cases. $78.68 \%$ had macrovascular complications, of which $53.12 \%$ were men. Diabetic neuropathy was the most common.seen in $52.63 \%$ cases

\section{Reference}

1. Jessica Barbieri, Paula CaitanoFontela et al.,Anaemia in patients with Type 2 DM. Hindawi publishing corporation, Anemia, Volume 2015, Article ID354737,7 pages

2. M. Andrews and M. Arredondo, "Ferritin levels and he[pcidin mRNA expression in peripheral mononuclear 
cells from anemic type 2 diabetic patients," Biological Trace Element Research, vol. 149, no. 1, pp. 1-4, 2012.

3. Type 2 Diabetes in the Young; The evolving epidemicZachary T. Bloomgarden, MDDiabetes Care 2004 Apr; 27(4): 998-1010. https://doi.org/10.23 37/diacare.27.4.998

4. HorikawaY, OdaN, CoxNJ, LiX, OrhoMelander M, Hara M, Hinokio Y, Lindner TH, Mashima H, Schwarz PE, del Bosque-Plata L, Horikawa Y, Oda Y, Yoshiuchi I, Colilla S, Polonsky KS, Wei S, ConcannonP, Iwasaki N, Schulze J, Baier LJ, Bogardus C, Groop L, Boerwinkle E, Hanis CL, Bell GI: Genetic variation in the gene encoding calpain-10 is associated with type 2 diabetes mellitus. Nat Genet 26:163-175, 2000

5. CapponJP, IppE, BraselJA, CooperDM: Acuteeffects of high fat and high glucose meals on the growth hormone response to exercise. J ClinEndocrinolMetab 76: 1418-1422, 1993

6. Schmitz KH, Jacobs DR Jr, Hong CP, Steinberger J, Moran A, SinaikoAR: Association of physical activity with insulin sensitivity in children. Int $J$ ObesRelatMetabDisord 26:1310-1316, 2002

7. Davenport J. Macrocyticanemia. Am Fam Physician. 1996;53(1):155-162

8. Craig KJ, Williams JD, Riley SG, Smith H, Owens DR, Worthing D; Anemia and Diabetes in the Absence of Nephropathy Diabetes Care May 2005; 28 (5) 1118-23

9. Sharif A, Younus S, Baig K, Ali NH; Prevalence and Risk of Anemia in Type-2 Diabetic Patients. Health 2014; 6: 1415-9.
10. Rathod GB, Parmar P, Rathod S, Parikh A; Prevalence of anemia in patients with Type 2 Diabetes Mellitus at Gandhinagar, Gujarat, India. International Archives of Integrated Medicine 2016; 3(3): 12-6.

11. Griac K, Williams JD, Riley SG; Anemia and Diabetes in the Absence of Nephropathy. Diabetes Care 2005; 28: 18-23

12. Al Salman .Anemia in patients with DM: Prevalence and progression. General Med 2015, 3:1

13. Jonas, Smith, Nag, Bilous, Winship, et al.,(2010) Prevalence and nature of anemia in a prospective, population - based sample of people with diabetes(TAD) study. Diabet Med 27:655-659

14. Merlin, Richard, Con, Lynda et al., (2004) Anamia in patients with type 1 diabetes. $J$ ClinEndocrinolMetab 89;4359-63

15. Adejumo BI, Dimkpa U, Ewenighi CO, Onifade AA, Mokogwu AT, Erhabor TA et al.; Incidence and Risk of Anemia in Type-2 Diabetic Patients in the Absence of Renal Impairment. Health Journal 2012; 4:204-308.

16. Bonakdaran S, Gharebaghi M, Vahedian M; Prevalence of Anemia in Type-2 Diabetes and Role of Renal Involvement. Saudi Journal of Kidney Diseases and Transplantation 2011; 22: 286-90.

17. Manoj Gulati, Navneet Agrawal, Study of prevalence of anaemia in patients with Type 2 DM, SchJ.App.Med.Sci., 2016;495F0:1826-29

18. Thomas MC, MacIsaac RJ, Tsalamandris C; Unrecognized anemia in patients with diabetes: A cross-sectional survey. Diabetes Care 2003; 26(4): 1164-9.

\section{How to cite this article:}

Hemani K and Kannan Rajendran (2017) ' A Study Of Anemia And Diabetic Complications In Patients With Type Iidiabetes Mellitus In A Tertiary Care Centre', International Journal of Current Advanced Research, 06(05), pp. 3592-3594.

DOI: http://dx.doi.org/10.24327/ijcar.2017.3594.0323 